\title{
Snow model comparison to simulate snow depth evolution and sublimation at point scale in the semi-arid Andes of Chile
}

\author{
Annelies Voordendag ${ }^{1 *}$, Marion Réveillet ${ }^{2 * *}$, Shelley MacDonell $^{2}$, and Stef Lhermitte ${ }^{1}$ \\ ${ }^{1}$ Department of Geoscience and Remote Sensing, Delft University of Technology, Delft, The Netherlands \\ ${ }^{2}$ Centro de Estudios Avanzados en Zonas Áridas (CEAZA), ULS-Campus Andrés Bello, Raúl Britan 1305, La Serena, Chile \\ *now at: Department of Atmospheric and Cryospheric Sciences (ACINN), University of Innsbruck, Innsbruck, Austria \\ ***now at: Univ. Grenoble Alpes, Université de Toulouse, Météo-France, CNRS, CNRM, Centre d'Etudes de la Neige, 38100 \\ Grenoble, France
}

Correspondence: Shelley MacDonell (shelley.macdonell@ceaza.cl)

\begin{abstract}
Physically-based snow models provide valuable information on snow cover evolution and are therefore key to provide water availability projections. Yet, uncertainties related to snow modelling remain large as a result of differences in the representation of snow physics and meteorological forcing. While many studies focus on evaluating these uncertainties, issues still arise, especially in environments where sublimation is the main ablation process. This study evaluates a case study in the semi-arid Andes of Chile and aims to compare two snow models with different complexities, SNOWPACK and SnowModel, at a local point, over one snow season. Their sensitivity relative i) to physical calibration for albedo and fresh snow density and ii) to forcing perturbation is evaluated based on ensemble approaches. Results indicate larger uncertainty depending on the model calibration than between the two models (even though the significant differences in their physical complexity). We also confirm the importance of albedo parameterization, even though ablation is driven by sublimation. SnowModel is particularly sensitive to this choice as it strongly affects both the sublimation and the melt rates. However, the day of snow-free snow surface is not sensitive to the parameterization as it only varies every eight days. The albedo parameterization of SNOWPACK has stronger consequences on melt at the end of the season leading to a date difference of the end of the season of 41 days. However, despite these differences, the sublimation ratio ranges are in agreement for the two models: 42.7-63.5\% for SnowModel and 51.3 and $64.6 \%$ for SNOWPACK, and are related to the albedo calibration choice for the two models. Finally, the sensitivity of both models to the forcing data was in the same order of magnitude and highly influenced by the precipitation uncertainties.
\end{abstract}

\section{Introduction}

Snow models provide valuable information on snow cover evolution and are therefore key to quantify runoff and provide accurate water availability projections. Several models, with different complexities, from empirical to physical approaches, have been developed to simulate snow depth changes. Empirical approaches, such as degree-day models (e.g. Braithwaite and Olesen, 1989; Hock, 2003) are based on a simple statistical relationship to positive air temperatures to simulate snow melt. Comparatively, physically-based approaches consider all energy flux exchanges at the snow surface by solving the surface 
https://doi.org/10.5194/tc-2021-9

Preprint. Discussion started: 26 January 2021

(c) Author(s) 2021. CC BY 4.0 License.

(c) (i)

energy balance equation (Oke, 2002). These approaches, coupled with snow models, enable a more complete understanding of snow physical processes and are essential for understanding the interaction between snow cover evolution and climate change.

Physically-based snow models have different complexities in their physical representations, from a single layer approach (e.g. Strasser and Marke, 2010), to more sophisticated multi-layer detailed models representing the evolution of snow microstructure and the layering of snow physical properties (e.g. Bartelt and Lehning, 2002; Vionnet et al., 2012), leading to a wide variety of snow models with a wide variety of parameterizations. In a snow model intercomparison study, Etchevers et al. (2004) highlighted the importance of parameterization choice, especially regarding the net longwave and albedo characterisation. After comparing 33 snow models, Rutter et al. (2009) concluded that no universal 'best' model exists and model performance strongly depends on the study site.

In addition to the development of new models, many studies have focused on model improvements offering different parameterizations in a single model (e.g. Douville et al., 1995; Dutra et al., 2010). In such frameworks, often many parameters need to be calibrated and are often difficult to be set according to local measurements, such as the albedo and aerodynamic roughness length (Brock et al., 2000, 2006). To address this issue, and to consider and quantify parameter uncertainty propagation in simulated snow depth changes, recent studies have started to use ensemble approaches. Here models are evaluated based on different likely combinations of values of variables such as snow albedo, snow compaction, fresh snow density and liquid water transport (e.g. Essery et al., 2013; Lafaysse et al., 2017; Günther et al., 2019).

In addition, forcing data uncertainty has a significant influence on the simulated snow depth changes (e.g. Magnusson et al., 2015; Raleigh et al., 2015; Günther et al., 2019) and needs to be considered in model evaluations. While point scale simulations forced by direct observations generally reduce forcing uncertainties, measurement errors can be considerable due to the complexity of both measuring certain parameters as well as maintaining measurement sites (e.g. for precipitation (MacDonald and Pomeroy, 2007; Smith, 2007; Wolff et al., 2015), sensor inclination (Weiser et al., 2016) or sensor failure). Methods such as stochastic perturbation with random noise (e.g. Charrois et al., 2016) or following a uniform or normally distributed bias with different magnitudes (e.g. Raleigh et al., 2015) can be used to build an ensemble of meteorological forcing and explicitly simulate the consequence of forcing uncertainty on the simulated snow depth (e.g. Charrois et al., 2016; Zolles et al., 2019; Günther et al., 2019).

Despite past efforts to improve snow models and quantify uncertainty propagation, the uncertainties regarding snow physics representation and meteorological forcing remains (e.g. Essery et al., 2013; Raleigh et al., 2015; Günther et al., 2019); especially in regions where sublimation is the main ablation process.

This study aims to evaluate two physical snow models with different complexities, considering calibration and forcing uncertainties. There we simulate snow depth changes in the Andes of Chile using data from an automated weather station. In this semi-arid region, snow model uncertainty is a key concern as snow melt is an essential water resource for the population (Favier et al., 2009). Despite this importance, quantifying and understanding the snow cover evolution remains limited and challenging due to i) high sublimation rates related to strong solar radiation, cold air temperatures, and high wind speeds (e.g. MacDonell et al., 2013a; Réveillet et al., 2020), and ii) shallow snow depths due to very low precipitation amounts (Scaff et al., 2017; Réveillet et al., 2020; Ayala et al., 2017). In previous studies the effect of wind on snow cover pattern distribution has been 
https://doi.org/10.5194/tc-2021-9

Preprint. Discussion started: 26 January 2021

(c) Author(s) 2021. CC BY 4.0 License.

(c) (i)

assessed by Gascoin et al. (2013) and the relative importance of melt versus sublimation has been studied over one catchment by Réveillet et al. (2020), both making use of the physically-based snow model SnowModel (Liston and Elder, 2006b). The study performed by Mengual Henríquez (2017) assessed the snow types in different Chilean regions with SNOWPACK (Bartelt and Lehning, 2002; Lehning et al., 2002b, a). Nevertheless, an accurate assessment of different snow models' sensitivity to parameterization choice or input forcing is currently missing, although it is expected to have a large impact.

In this work, the sensitivity of SnowModel and SNOWPACK, the common snow models previously used in this region, is assessed in function of parameterization choices and forcing uncertainty. First, both models are run with different combinations of parameterizations to assess the uncertainty of parameterizations (Sect. 3.2). Second, forcing uncertainty propagation in the snow model is considered by running the models with 1000 sets of perturbed forcing (Sect. 3.3. Considering model sensitivities to calibration and forcing, models are compared and differences are discussed (Sect. 3.4).

\section{Study area and data}

We assess the sensitivity of both models using data from an AWS over the snow season of 2017. First this study area and the meteorological observations are described, followed by the data preprocessing procedure.

\subsection{Study area}

The study area is located in the La Laguna catchment, in the Chilean Coquimbo region, close to the Argentinian border (Fig. 1a). To assess the sensitivity we use data from the Tapado Automatic Weather Station (AWS), a permanent station since 2009 located close to the terminus of the Tapado Glacier at $30^{\circ} \mathrm{S}, 69^{\circ} \mathrm{W}, 4306 \mathrm{~m}$ a.s.l. (Fig. 1c). The site shows a complex topographic setting with average (maximum) wind speeds of $4.2 \mathrm{~m} \mathrm{~s}^{-1}\left(>15 \mathrm{~m} \mathrm{~s}^{-1}\right)$ in 2017 and little precipitation $(<200$ $\mathrm{mm} \mathrm{a}^{-1}$ ) that arrives as snow during fewer than 10 events per year. Precipitation events mainly occur during the winter season (>90\%) (Rabatel et al., 2011; Réveillet et al., 2020). Therefore the area surrounding the AWS is only covered with snow in austral winter. At this elevation, no vegetation is observed. 
https://doi.org/10.5194/tc-2021-9

Preprint. Discussion started: 26 January 2021

(c) Author(s) 2021. CC BY 4.0 License.
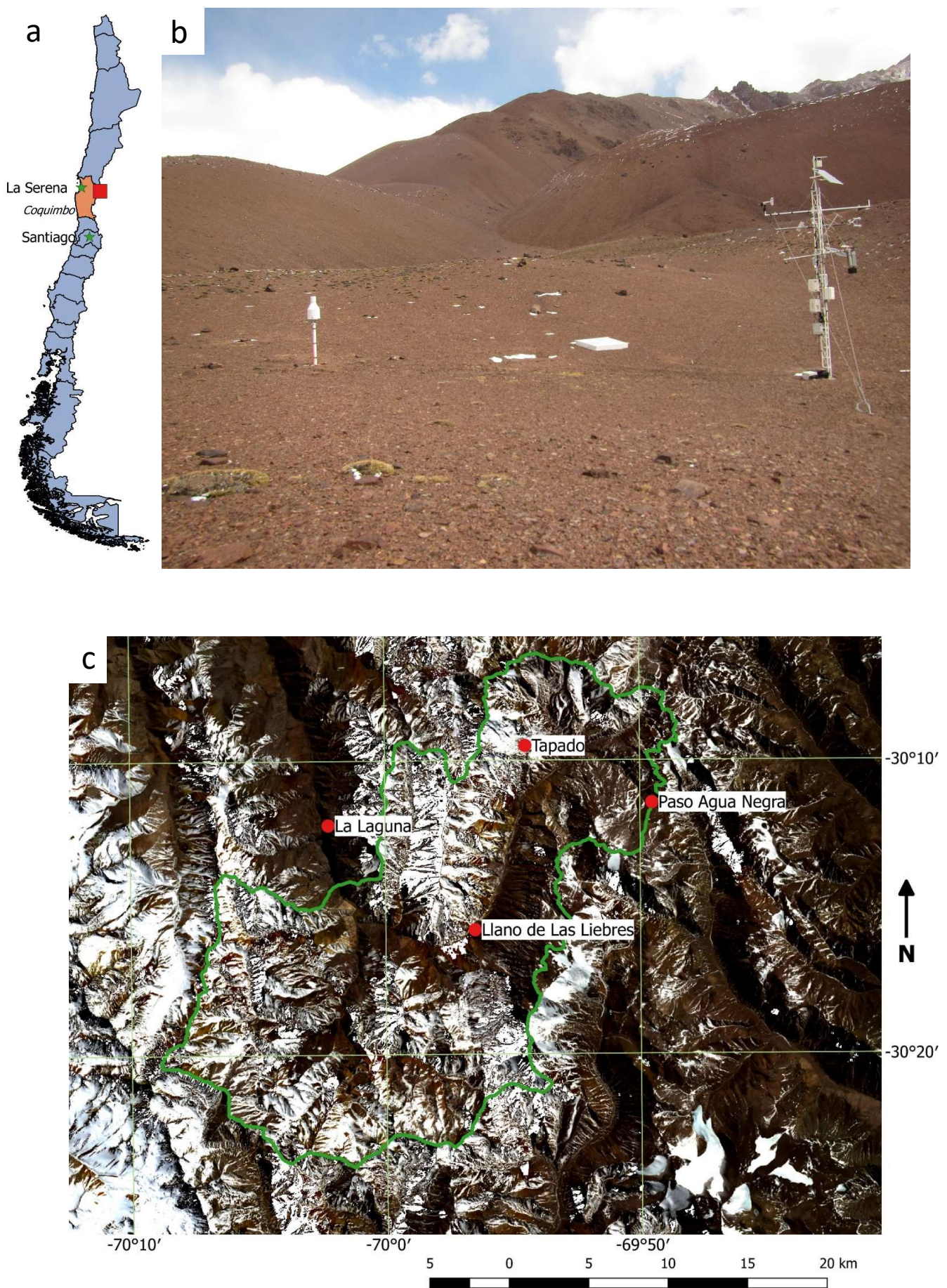

Figure 1. a) Map of Chile with the Coquimbo Region (orange) and the study area location (red box). b) Tapado AWS at the 26th of April 2018 showing the Geonor precipitation gauge (left) which is $10 \mathrm{~m}$ from the central mast of the AWS (right). c) Map of the borders of the La Laguna catchment (green), with the AWS locations (red points). Landsat 8 images of 29 August 2017 are used as background and maps and photo are made by A. Voordendag. 
https://doi.org/10.5194/tc-2021-9

Preprint. Discussion started: 26 January 2021

(c) Author(s) 2021. CC BY 4.0 License.

(c) (i)

\subsection{Meteorological observations}

The meteorological forcing data consisted of hourly mean values of air temperature (TA), relative humidity (RH), incoming shortwave radiation $\left(S_{\downarrow}\right)$, incoming longwave radiation $\left(L_{\downarrow}\right)$, wind speed (WS), wind direction (WD) and air pressure (PA) measured by the AWS (Fig. 2, Table S1.1 in the Supplementary Material (SM)). Precipitation forcing consisted of hourly data by a Geonor rain gauge (Fig. 1b). During the snow season, defined as the period with snow on the ground (i.e. between 10 May and 6 November 2017), the station recorded meteorological observations continuously except for the TA and RH, for which gaps have been filled using three nearby AWSs (Fig. 1c, Sect. 2.3).

Hourly snow depth (SD), reflected shortwave radiation $\left(S_{\uparrow}\right)$ and six-hourly means of snow water equivalent (SWE) were also recorded at the station and used for model calibration and evaluation. SWE was measured with a CS725 sensor by Campbell Scientific which passively detects the change in naturally emitted terrestrial gamma radiation from the ground after it passes through snow cover. It provided two independent SWE observations measuring both potassium and thallium gamma rays (Wright, 2011). The uncertainty given by the manufacturer is $\pm 15 \mathrm{~mm}$ from 0 to $300 \mathrm{~mm}$ and $\pm 15 \%$ from 300 to $600 \mathrm{~mm}$, but differences of up to $82 \mathrm{~mm}$ w.e. between gamma ray measurements at $\sim 300 \mathrm{~mm}$ w.e. were measured. The manufacturer suggests that the output with the higher count is generally the most reliable, which were the potassium gamma rays measurements (Randall, 2018, personal communication). We display both data sets and estimate an accuracy of $\pm 25 \mathrm{~mm}$ for this data set.

\subsection{Preprocessing of forcing data}

When modelling the snow evolution, we covered a period (5 May to 30 Nov 2017) extending outside the snow season to allow a five day spin-up phase to enable the model to reach a physical equilibrium with the applied forcing. Since continuous data are required for both snow models, preprocessing was necessary to fill the gaps in the TA and RH data sets (23 June 11:00 and 31 October 10:00 due to sensor failure) and to correct the wind-induced undercatch in the precipitation data. Therefore, TA and RH data was interpolated based on lapse rates from nearby AWSs (Agua Negra (4774 m a.s.l.), Llano de las Liebres (3565 $\mathrm{m}$ a.s.1.) and La Laguna (3209 m a.s.1.; Fig. 1c).

For TA, a daily moist adiabatic lapse rate was calculated using TA measured at La Laguna and Paso Agua Negra AWSs (1565 m elevation difference) between 2014 and 2017. We fitted a sinusoidal trend over these lapse rates for the 4-year period and found daily lapse rates with a maximum of $-6.9^{\circ} \mathrm{C} \mathrm{km}^{-1}$ in winter and a minimum of $-8.0^{\circ} \mathrm{C} \mathrm{km}^{-1}$ in summer. These daily lapse rates were subsequently applied to TA observations of Llano de las Liebres AWS which is the only AWS that covers the entire period of missing data in 2017. For RH a similar approach was applied using the lapse rate of the daily dew point temperature between the Paso Agua Negra and La Laguna AWSs and applying it to data measured at the Llano de las Liebres AWS. Dew point temperature was converted to RH following Liston and Elder (2006a). Evaluation of this lapse rate interpolation, based on 1638 overlapping observations at Tapado, shows an uncertainty (i.e. RMSE) of $2.8^{\circ} \mathrm{C}$ and $9.97 \%$ for TA and RH respectively. 
https://doi.org/10.5194/tc-2021-9

Preprint. Discussion started: 26 January 2021

(c) Author(s) 2021. CC BY 4.0 License.

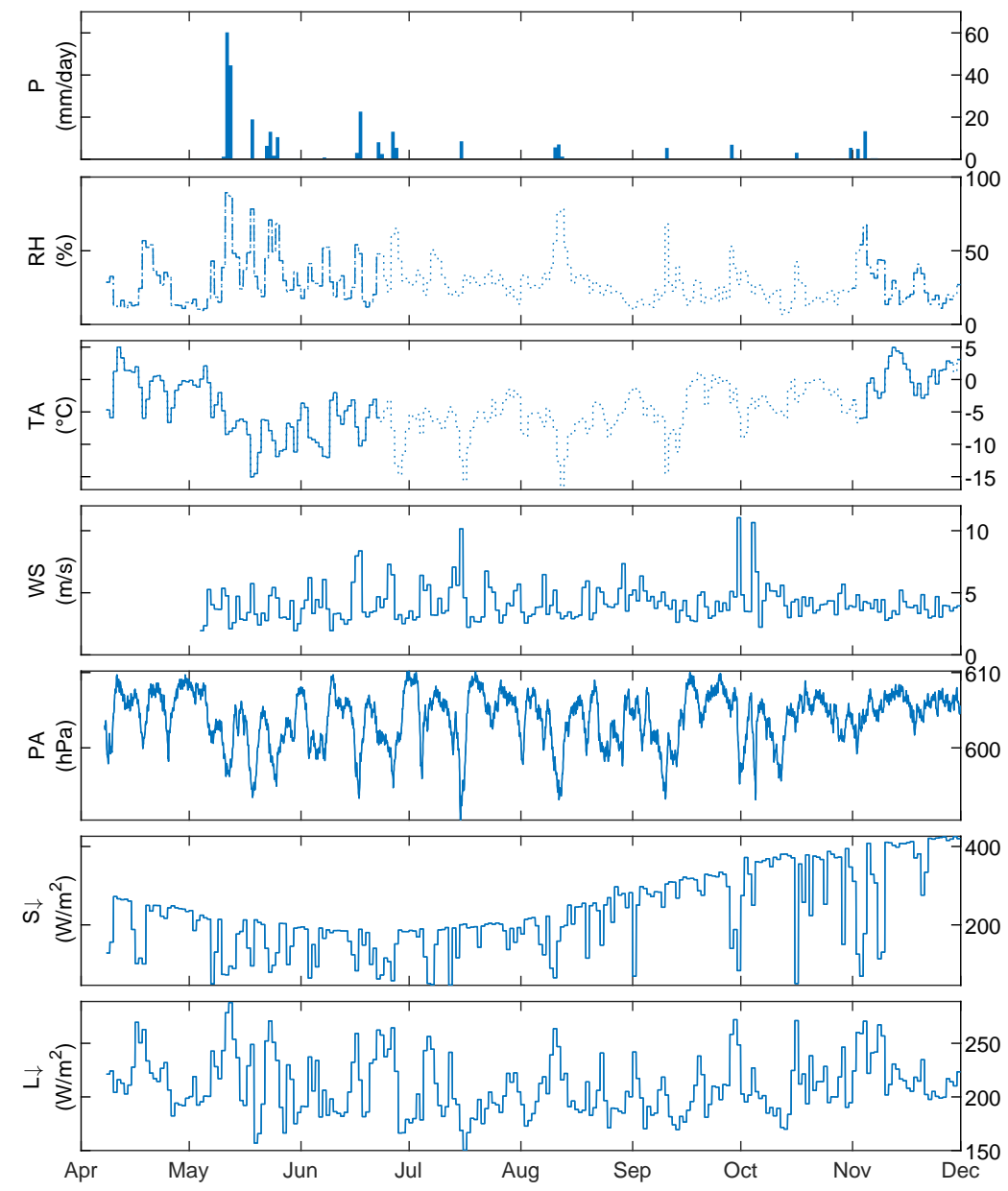

Figure 2. Meteorological observations at Tapado with with daily precipitation (P), average daily relative humidity (RH), temperature (TA), wind speed (WS), air pressure (PA), incoming shortwave radiation $\left(S_{\downarrow}\right)$ and incoming longwave radiation $\left(L_{\downarrow}\right)$ from April to December 2017. Dotted lines indicate the TA and RH interpolations.

Since the precipitation observations were strongly influenced by wind, an undercatch in the precipitation gauge is likely (e.g., MacDonald and Pomeroy, 2007; Smith, 2007; Wolff et al., 2015). Therefore the Geonor precipitation observations were corrected by applying the catch efficiency factor $C E$ using MacDonald and Pomeroy (2007, Eq. (3)) based on WS observations adjusted from the wind sensor height $(5.4 \mathrm{~m})$ to gauge height using a logarithmic wind profile (e.g., Lehning et al., 2002a) and 
https://doi.org/10.5194/tc-2021-9

Preprint. Discussion started: 26 January 2021

(c) Author(s) 2021. CC BY 4.0 License.

(c) (i)

a roughness length of $0.001 \mathrm{~m}$ :

$C E_{\text {Geonor }}=1.01 \exp (-0.09 W S)$

This corrected precipitation is hereinafter referred to as reference precipitation $\left(P_{r e f}\right)$. Precipitation uncertainty was quantified as the difference between the uncorrected, observed precipitation and the precipitation reconstructed from the SWE observations, which was computed using the cumulative positive SWE (potassium) changes during precipitation events (detected by the Geonor T-200B). This cumulative SWE approach reduced the inclusion of deposition of drifting snow resulting which would result in an overestimation of SWE. Based on this approach, the precipitation ranges between $190 \mathrm{~mm} \mathrm{a}^{-1}$ (from precipitation gauge) and $470 \mathrm{~mm} \mathrm{a}^{-1}$ (from SWE reconstruction). The difference between these values is likely caused by the location offset between the precipitation gauge and the SWE and SD sensor (Fig. 1b), as the AWS is placed in a concave area that collects more snow than the Geonor precipitation gauge.

\section{Methods}

\subsection{Model descriptions}

\subsubsection{SNOWPACK}

SNOWPACK was developed by the Swiss Federal Institute (SLF) for Snow and Avalanche Research (Bartelt and Lehning, 2002; Lehning et al., 2002a, b). It is a one-dimensional model, but can be implemented in the spatially distributed, threedimensional snow cover and earth surface model Alpine3D (Lehning et al., 2006). SNOWPACK includes a MeteoIO preprocessing library for meteorological data (Bavay and Egger, 2014) which was not used, as we implemented a homogeneous preprocessing approach for both models (see Sect. 2.3). SNOWPACK is a physically-based model which has the ability to simulate snow physical properties (e.g. snowpack temperature, layer thickness, snow microstructure and density) and snow processes (e.g. refreezing, sublimation, melt, evaporation) for multiple layers, which are merged if layers become too thin. Sublimation and evaporation are calculated for the top element of the snowpack and melt is simulated using a water transport bucket scheme. In this bucket scheme, all the liquid water exceeding a threshold water content is transported downward in the snowpack or soil (Wever et al., 2014). An extensive description of the model can be found in Bartelt and Lehning (2002); Lehning et al. (2002a, b).

\subsubsection{SnowModel}

SnowModel is a spatially distributed snowpack evolution modelling system composed of four submodels MicroMet, EnBal, SnowPack and SnowTran3D (Liston and Elder, 2006b). MicroMet is preprocessing library for meteorological data interpolation, which was not used in this study as we focused on one location only while we implemented a homogeneous preprocessing approach for both models (see Sect. 2.3). EnBal calculates standard surface energy balance exchanges (Liston and Hall, 1995). SnowModel's SnowPack subroutine is a single or multi-layer (max. six layers) snowpack evolution and runoff model that 
https://doi.org/10.5194/tc-2021-9

Preprint. Discussion started: 26 January 2021

(C) Author(s) 2021. CC BY 4.0 License.

(c) (i)

describes snowpack changes in response to precipitation and melt fluxes defined by MicroMet and EnBal (Liston and Hall, 1995; Liston and Elder, 2006b). In SnowModel, the melted snow is redistributed through the new snow depth up to a maximum density threshold of $550 \mathrm{~kg} \mathrm{~m}^{-3}$. Any additional melt water is added to the runoff. In this study the model was run with the maximum of snow layers (i.e. six layers) to be comparable with the multiple amount of layers in SNOWPACK. Finally, the three-dimensional model to simulate snow erosion and deposition SnowTran3D (Liston and Sturm, 1998) is not activated in this study; this choice is discussed in Sect. 5.2.

\subsection{Model calibration}

To assess the sensitivity of both models to parameterization choice and input uncertainty, we applied a three step approach. First, we calibrated both models similarly to allow later comparisons (Sect. 3.2.1). Second, we varied the parameterization settings of each to determine the effect of parameterization choice (Sect. 3.2.2). Third, we implemented forcing perturbations (Sect. 3.3) to evaluate model sensitivities to the meteorological forcing uncertainties. The combination of sensitivity analysis to model calibration and meteorological forcing allowed to evaluate and compare the two models (Sect. 3.4).

\subsubsection{Parameter values used in both models}

Initially, both models were calibrated using similar parameters to facilitate intercomparison. These parameters were derived from observations or previous studies (Table 1). For example, the soil albedo was set to 0.15 , as this is the average observed albedo at the moment when there is no snow. The observed daily albedo is defined as the daily sum of the average hourly reflected shortwave $\left(S_{\uparrow}\right)$ divided by the daily sum of average hourly incoming shortwave radiation $\left(S_{\downarrow}\right)$ (Fig. 3e,f). In the absence of roughness length measurements, the roughness length of the bare soil is set to $0.020 \mathrm{~m}$, corresponding to the default roughness length of pebbles and rocks in SnowModel. As surface ground temperature measurements are not available, we set it to $-1{ }^{\circ} \mathrm{C}$ in both models. $-1^{\circ} \mathrm{C}$ is the default value in SnowModel and ensures that the first snow does not immediately melt.

Atmospheric stability and roughness length $\left(z_{0}\right)$ are key parameters in semi-arid regions where sublimation is an important process. As SnowModel only allows atmospheric stability corrections based on the Richardson number, we opted for this method and similar roughness lengths in both models to assure intercomparability. The snow roughness length was fixed to $0.001 \mathrm{~m}$ based on an earlier sensitivity study (Réveillet et al., 2020) and unpublished eddy covariance measurements (MacDonell et al., 2013a). Additionally, the sensitivity of both models to roughness length is further analysed in Sect. S3 of the SM, as it was not used to select the final model configurations.

\subsubsection{Sensitivity analysis of variable parameterizations}

To assess the impact of the parameterizations on the snowpack simulation, an ensemble approach based on different combinations of albedo and snow density parameterizations was used (e.g. Essery et al., 2013; Lafaysse et al., 2017). The choice to limit the sensitivity test to these two parameters is discussed in Sect. 5.2. 
https://doi.org/10.5194/tc-2021-9

Preprint. Discussion started: 26 January 2021

(c) Author(s) 2021. CC BY 4.0 License.

(c) (i)

Table 1. SNOWPACK and SnowModel parameter characteristics. The possible snow albedo parameterizations and fresh snow density models are described in Sect. S4.

\begin{tabular}{lll}
\hline & SNOWPACK & SnowModel \\
\hline Soil albedo & 0.15 (calibrated) & 0.15 (calibrated) \\
Max/min snow albedo & None & $0.6 / 0.9$ (calibrated) \\
Atmospheric stability correction model & Richardson number & Richardson number (default) \\
Roughness length (soil) & $0.02 \mathrm{~m}$ & $0.02 \mathrm{~m}$ (default) \\
Roughness length (snow) & $0.001 \mathrm{~m}$ (calibrated) & $0.001 \mathrm{~m}$ (calibrated) \\
Surface ground temperature & $-1^{\circ} \mathrm{C}$ & $-1^{\circ} \mathrm{C}$ (default) \\
Thermal conductivity & Default & Multilayer subroutine \\
Wind erosion/snow transport by wind & Off & Off \\
Maximum number of snow layers & Unlimited & 6 layers \\
Fresh snow density parameterizations & 5 options & 1 default options and 2 from SNOWPACK \\
Albedo parameterizations & 6 options, 4 used & 2 options \\
Simulated ablation processes & Sublimation, runoff, evaporation & Sublimation, runoff \\
Water transport in snowpack & Bucket scheme (default) & Default \\
\hline
\end{tabular}

For SNOWPACK, 20 runs were performed over the 2017 season based on four different albedo and five fresh snow density parameterizations. Each of the albedo parameterizations is based on empirical relations derived from continuous observations at Weissfluhjoch (Lehning et al., 2002a) or on grain size (Schmucki et al., 2014), while the fresh snow parameterizations are empirical formulas depending on the TA, RH, WS and surface temperature. More details are found in the Sect. S4 (SM) and the mentioned references.

For SnowModel, an ensemble of six simulations was run, considering two albedo and three snow density parameterizations. The albedo parameterizations range between 0.6 and 0.9 depending i) on TA solely (more details in Liston and Hall (1995), Liston and Elder (2006b) and in Sect. S4 (SM)) or ii) on TA and time (Strack et al., 2004, and Sect. S4). SnowModel's default fresh snow density parameterization depends on the wet bulb temperature, but we included two fresh snow density parameterizations from SNOWPACK depending on TA, RH, WS and surface temperature to test the model more extensively. In these additional parameterizations, we preserved the SnowModel defaults for minimum $\left(50 \mathrm{~kg} \mathrm{~m}^{-3}\right)$ and maximum fresh snow density $\left(158.5 \mathrm{~kg} \mathrm{~m}^{-3}\right)$.

Each of the ensemble simulations was forced by the unperturbed measurements $\left(P_{r e f}, \mathrm{TA}, \mathrm{RH}, \mathrm{PA}, \mathrm{WS}, \mathrm{WD}, S_{\downarrow}, L_{\downarrow}\right)$ described in Sect. 2.3 and evaluated by comparing the model output of SD, SWE and albedo with the corresponding observations. Based on this evaluation the simulation with the lowest $R M S E$ and highest $R^{2}$ between the observed and modelled albedo is chosen as the reference for the forcing sensitivity analysis discussed in Sect. 3.3. 
https://doi.org/10.5194/tc-2021-9

Preprint. Discussion started: 26 January 2021

(C) Author(s) 2021. CC BY 4.0 License.

(c) (i)

Table 2. Forcing data for the snow models with the corresponding uncertainty $\sigma$ used in the MC simulation. The uncertainties of PA, WS, WD, $S_{\downarrow}$, and $L_{\downarrow}$ are the uncertainties as given by the manufacturers and for TA and RH, the uncertainties as described in Sect. 2.3 are used.

\begin{tabular}{|l|l|}
\hline Observation & Uncertainty $\sigma$ in $\mathrm{MC}$ simulation \\
\hline Accumulated precipitation (P) & Between 190 and $470 \mathrm{~mm} \mathrm{a}^{-1}$, Fig. S2.1 \\
Air pressure (PA) & $\pm 1.0 \mathrm{hPa}$ \\
Air temperature (TA) & $\pm 2.8^{\circ} \mathrm{C}$ \\
Incoming longwave radiation $\left(L_{\downarrow}\right)$ & $10 \%(95 \%$ confidence level) \\
Incoming shortwave radiation $\left(S_{\downarrow}\right)$ & $5 \%(95 \%$ confidence level) \\
Relative humidity (RH) & $\pm 9.97 \% \mathrm{RH}$ \\
Wind speed (WS) & $\pm 0.3 \mathrm{~m} / \mathrm{s}$ \\
Wind direction (WD) & $\pm 3^{\circ}$ \\
\hline
\end{tabular}

\subsection{Forcing uncertainty estimation}

To assess the model sensitivity to meteorological measurement uncertainties, the meteorological forcing presented in Sect. 2.3 is perturbed to generate an ensemble of 1000 forcing files. Therefore, all input variables except $\mathrm{P}$ were modified by adding hourly perturbations with a normal distribution $N\left(\mu=0, \sigma^{2}\right)$ with $\sigma$ the uncertainty reported in Table 2 .

The precipitation perturbations consisted of adding random variations $N\left(\mu=0, \sigma^{2}\right)$ to the reference precipitation $\left(P_{\text {ref,tot }}\right.$ : $278 \mathrm{~mm}$ w.e. $\mathrm{a}^{-1}$ ) based on the mean $P_{\text {mean }, t}$ between the reconstructed and measured hourly precipitation rate at every time step), $\sigma$ is considered a normally distributed random number, used as scaling factor and kept constant throughout the time series. Based on this scaling factor, the reference precipitation for each of the 1000 simulations $\left(P_{\text {sim, }, t}\right)$ at time $t$ is modified using:

$P_{\text {sim }, t}=P_{\text {ref }, t}+\sigma P_{\text {mean }, t}$

200 The precipitation distribution results are shown in Fig. S2.1a where the total precipitation at the end of the season is normally distributed around the reference precipitation (Fig. S2.1b).

Subsequently, based on the disturbed input data, 2000 snow model simulations are performed: 1000 with meteorological perturbations and 1000 with combined meteorological/precipitation perturbations. This setup was chosen to enable the differentiation between meteorological and precipitation uncertainties, which would be difficult in a combined approach where precipitation uncertainty would dominate.

\subsection{Model evaluation}

Model evaluation consists of comparing the model output of SD, SWE and albedo with the corresponding observations. For the parameterization uncertainty, this consists of evaluating the $R M S E$ and $R^{2}$ between the modelled and the observed albedo, to select the best reference for each model (i.e. twenty for SNOWPACK and six for SnowModel). It is chosen to only compare between modelled and observed albedo, as this ensures the best possible net shortwave radiation term in the energy balance 
https://doi.org/10.5194/tc-2021-9

Preprint. Discussion started: 26 January 2021

(c) Author(s) 2021. CC BY 4.0 License.

(c) (i)

equation. The forcing uncertainty is evaluated by comparing the differences of end of snow season. Last, the differences in ablation processes of the parameterizations are shown along with the energy fluxes of each reference simulation.

\section{Results}

\subsection{Sensitivity analysis of parameterizations}

215 The SW and SWE evaluation of the parameterization sensitivity analysis shows that the simulated SD and SWE are lower than the observations for both models (Fig. 3). This can be explained by the precipitation underestimation recorded by the precipitation gauge despite correcting for wind.

For SNOWPACK, the spread of the simulated SD from the 20 different calibrations is the largest at the beginning (i.e. May, June) and at the end of the snow season (i.e. October) (Fig. 3a). The date of snow free surface ranges between 8 October and 19 November (i.e. 41 days of differences), depending on parameterization choice, and covers the observed date of snow removal (i.e. 16 October). The different SNOWPACK parameterizations show a mean SD difference of $10 \mathrm{~cm}$ (which corresponds to 9\% of the total SD) between the minimum and maximum simulated SD (Fig. 3a), with a maximum of $84 \mathrm{~cm}$ observed at 12 May, the first day of snowfall. For the SWE, this corresponds to a mean difference of $23.9 \mathrm{~mm}$ w.e. (i.e $6.9 \%$ of the total SWE) (Fig. 3c). The large modelled SD spread in May and June can be explained by the different density parameterization choices as it is not apparent in the SWE simulations. The rapid decrease (3-8 $\mathrm{cm} \mathrm{d}^{-1}$ ) of snow depth until July, caused by compaction of the snowpack, is simulated by the majority of fresh snow density parameterizations, while only one fresh density parameterization models a more moderate compaction (Fig. 3a). From July onward, the measured snow depth reduces 10 centimetres per 25 days, which is only simulated by the fresh density parameterization that simulated moderate compaction before July.

The albedo evaluation (Fig. 3e) and corresponding statistics (Sect. S5) highlight one parameterization choice that outperforms all other parameterizations (i.e. $R M S E$ of 0.09 and $R^{2}$ of 0.85 compared to the albedo) in terms of snow compaction after snowfall events and albedo evolution (Fig. 3e). Therefore it is selected as the reference simulation (represented in bold lines in Fig. 3) for the forcing uncertainty simulations.

For SnowModel, the largest SD spread of the six ensembles occurs at the end of the simulated snow season (i.e. August and September) with complete snow removal between 19 and 27 September (i.e. 8 days) (Fig. 3b). The mean SD difference between the parameterizations is $11 \mathrm{~cm}$ (i.e. $10 \%$ of the total SD), with a maximum of $108 \mathrm{~cm}$ at 12 May, while for SWE the mean difference is $18 \mathrm{~mm}$ (i.e. $5.2 \%$ of the total SWE) with a maximum of $187 \mathrm{~mm}$ at 27 and 28 June (Fig. 3d).

A closer analysis of Fig. 3f shows that SnowModel's output clusters into two groups, where the grouping is determined by the albedo parameterization with limited influence of fresh snow density parameterizations. The differences between the two clusters increases as the difference in albedo between the parameterizations increases at the end of May. Quantitative analysis (Sect. S5) shows best performance scores for the time-evolution albedo approach in combination with the reference snow density parameterization ( $R M S E$ of 0.123 and $R^{2}$ of 0.776 ). Therefore, these are used as the reference simulation (bold line in Fig. 3). 
https://doi.org/10.5194/tc-2021-9

Preprint. Discussion started: 26 January 2021

(c) Author(s) 2021. CC BY 4.0 License.

(c) (i)
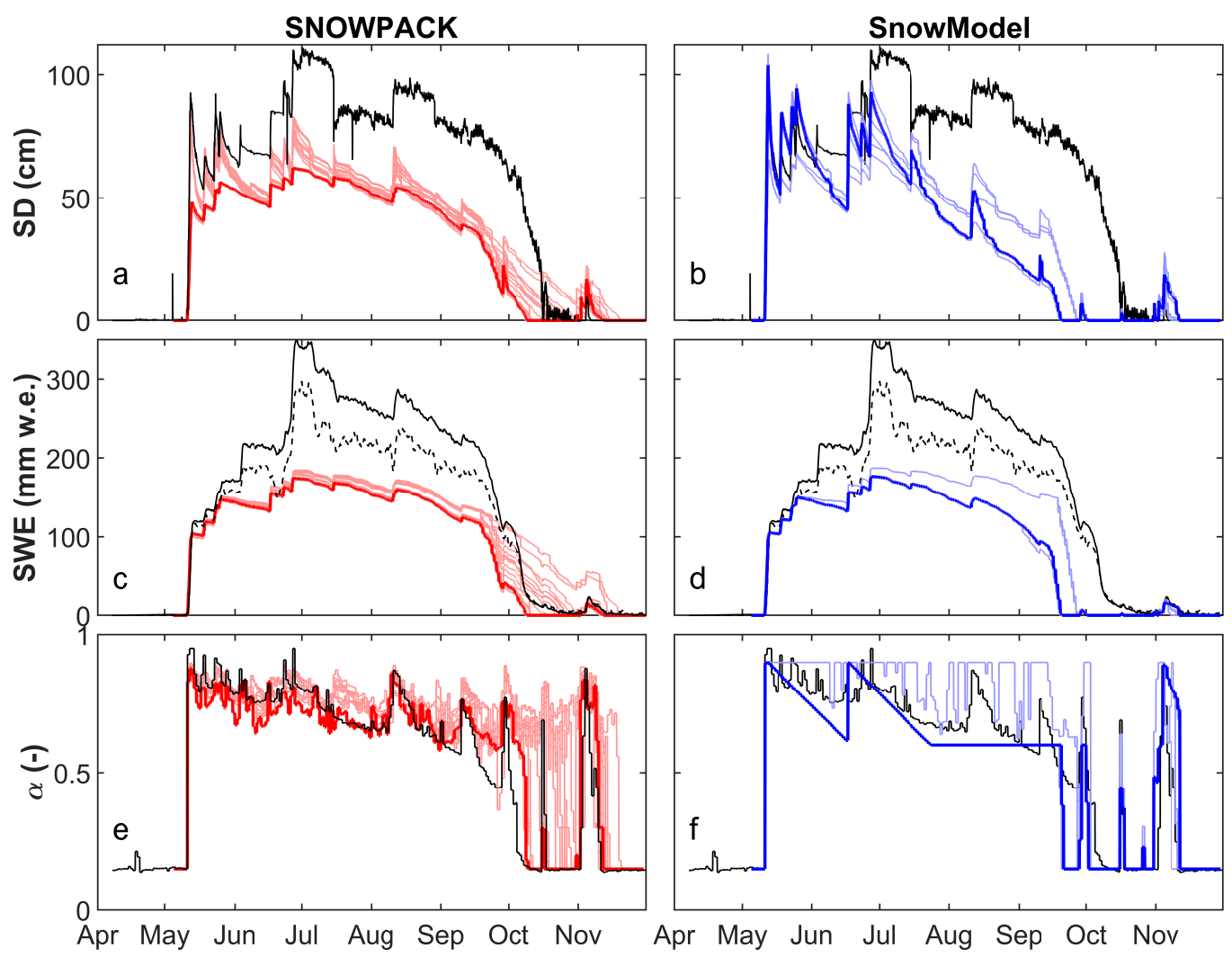

Figure 3. a-b) SD, c-d) SWE and e-f) albedo simulations (coloured) of the ensemble approaches for SNOWPACK (red) and SnowModel (blue) and observations (black). The bold coloured lines show the reference simulations chosen as the most optimal calibration according to the measured albedo. The dotted line of SWE indicates the less reliable (lower) SWE measurement from thallium rays (See Sect. 2.3).

Comparison of the SNOWPACK and SnowModel output shows similar SD variations attributed to snow density parameterizations that simulate low density snowfall with strong subsequent compaction. In reality, this happens at Tapado until June, followed by a different regime with denser fresh snow and less compaction. The biggest difference between the models, however, is the result of the albedo parameterizations. Where SnowModel relies on two simplistic albedo models based on albedo ranges, SNOWPACK relies on empirical relations which are not adapted to the Tapado climate. Nevertheless, the albedo of the reference run of SNOWPACK performs well in a semi-arid area. 
https://doi.org/10.5194/tc-2021-9

Preprint. Discussion started: 26 January 2021

(c) Author(s) 2021. CC BY 4.0 License.

(c) (i)

\subsection{Sensitivity analysis of forcing data}

\subsubsection{Without precipitation uncertainties}

The forcing perturbations without precipitation uncertainty show that SNOWPACK is more sensitive than SnowModel (Figures $4 \mathrm{a}, \mathrm{c}$ ) with mean SD/SWE differences of $7.9 \mathrm{~cm} / 17.5 \mathrm{~mm}$ w.e. for SNOWPACK and $5.7 \mathrm{~cm} / 7.7 \mathrm{~mm}$ w.e. for SnowModel. Also temporally, SNOWPACK shows larger sensitivities with larger spread uncertainty throughout the season, whereas for SnowModel the spread only emerges after mid-June. The forcing uncertainty results in complete snow removal simulations ranging from 25 Sep - 15 Oct (i.e. 19 days) for SNOWPACK and 17-20 September (i.e. 3 days) for SnowModel. The larger difference between both models in terms of complete snow removal is probably caused by precipitation input variations in SNOWPACK as result of TA, RH and $S_{\downarrow}$ constraints on snowfall in SNOWPACK. Since these requirements are not always met when the forcing is perturbed, it may result in precipitation variations in the input.

\subsubsection{With precipitation uncertainties}

The forcing perturbations with precipitation uncertainty shows that precipitation uncertainty has a much larger impact on SD and SWE ensemble spread (Fig. 4b,d). Averaged over the season this results in SD/SWE differences of $18.4 \mathrm{~cm} / 52.5 \mathrm{~mm}$ w.e. and $24.9 \mathrm{~cm} / 63.7 \mathrm{~mm}$ w.e. for SNOWPACK and SnowModel, respectively. Despite similar average spread over the entire season observed for both models, the range of the simulated day of free snow surface is higher for SNOWPACK (i.e. 24 September and 30 October) than for SnowModel (i.e. between 16 September and 6 October). Indeed, the spread at the end of the ablation season is diminishing for SnowModel while it is increasing for SNOWPACK.

\subsection{Consequences of the model choice and calibration on sublimation}

Ablation rates (Fig. 5) show that sublimation is the dominant driver for mass loss in both models until September (i.e. cold period), and followed by melt from September to the end of the season (i.e. end of November, and called the melting period). Note that for SNOWPACK, the first day of free snow surface of the reference run is 9 October and for SnowModel 20 September.

For SNOWPACK, the spread of the averaged sublimation rates corresponding to the ensemble runs from the first day of snow to 15 October ranges between 1.48 and $1.61 \mathrm{~mm}$ w.e. $\mathrm{d}^{-1}$ (Fig. 5a). During the cold period, when no melt occurs, all parameterizations result in similar sublimation amounts, with sublimation rates ranging between 1.16 and $1.32 \mathrm{~mm} \mathrm{w.e.}^{-1}$. At the end of the season, the total sublimation ranges between 142 and $179 \mathrm{~mm}$ w.e. (corresponding to 51.3 to $64.6 \%$ of the total ablation). During the melting period, the ensemble runs show a large spread of melt rates ranging between 2.15 to 9.05 $\mathrm{mm}$ w.e. $\mathrm{d}^{-1}$. The total amount of runoff is between 60 and $105 \mathrm{~mm}$ w.e. for SNOWPACK and this model also simulates evaporation, which contributes for 7.3 to $10.2 \%$ of total ablation (Fig. 5a).

For SnowModel, sublimation differences between the parameterizations are larger (Fig. 5b) with average sublimation rates from the first day of snow to 20 September ranging between 1.26 to $2.04 \mathrm{~mm}$ w.e. $\mathrm{d}^{-1}$, and it is worth noting that significant differences are also observed during the cold season (Fig. 5a). At the end of the winter season the sublimation totals range 

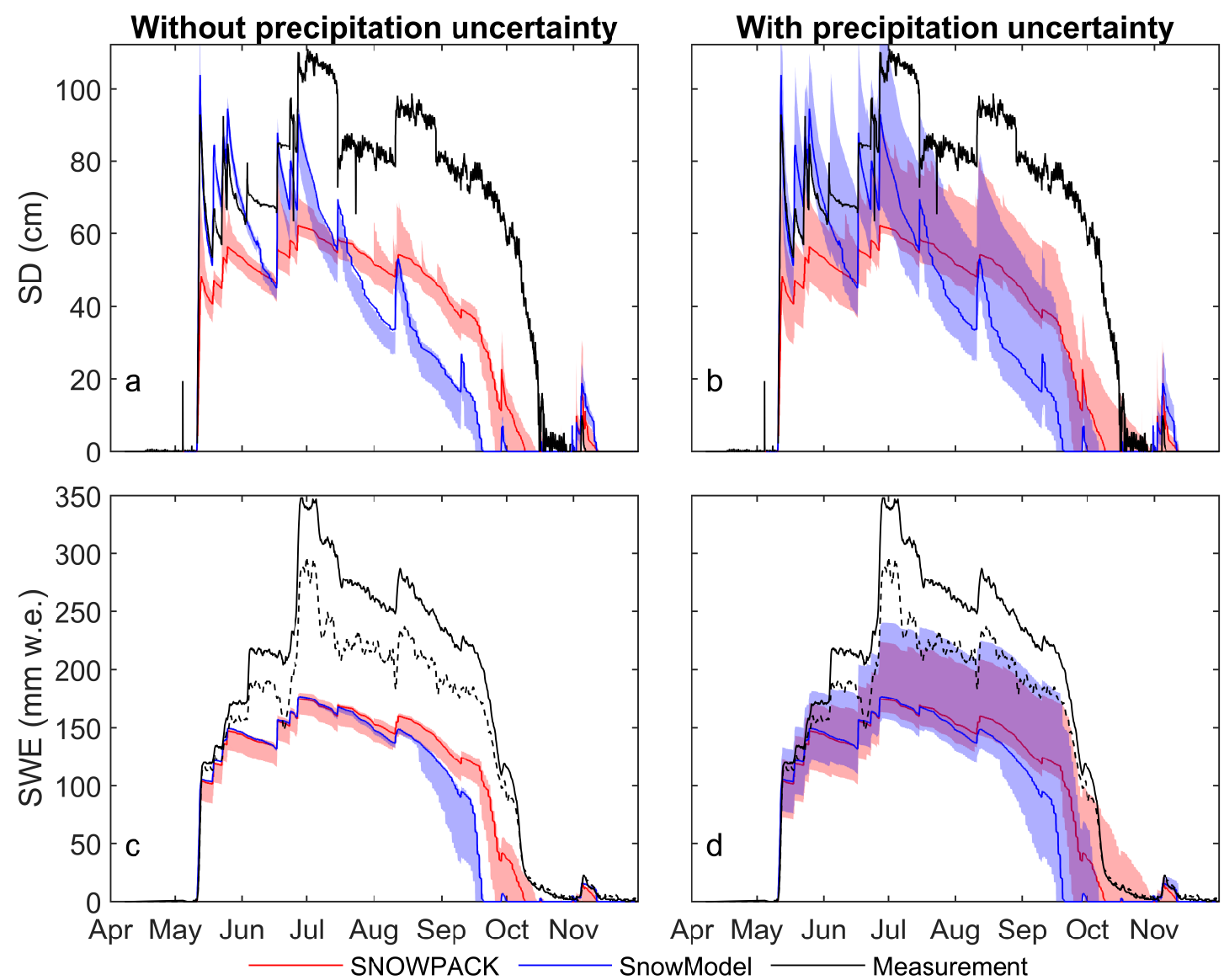

Apr May Jun Jul Aug Sep Oct Nov SnowModel - Measurement

Figure 4. Observed (black) and simulated (colour) SD and SWE by SnowPack and SnowModel forced by the 1000 ensembles of meteorological data. The reference run (see Sect. 3.2.2) of both models is the bold coloured curve. The shaded area corresponds to the 1000 runs of a)-b) snow depth and SWE c)-d) of SNOWPACK (red) and SnowModel (blue) for the MC run. a)-c) are without precipitation uncertainties and b)-d) are with precipitation uncertainties. The dotted line of SWE indicates the less reliable (lower) SWE measurement from thallium rays (See Sect. 2.3)

between 119 and $176 \mathrm{~mm}$ w.e. (which corresponds to 42.7 to $63.5 \%$ of the total ablation). Significant differences are also calculated during the melting period, when the simulated melt rate leads to a total melt difference of $58 \mathrm{~mm}$ w.e. at the end of the season.

The spread of the ensemble runs for both sublimation and melt simulated by SnowModel can be attributed to the choice of the albedo parameterization. While the ensemble calibration simulations do not lead to significant differences in the modelled end date of the snow season (i.e. difference of eight days), the parameterization strongly impacts the proportion of sublimation versus melt to the total ablation (Fig. 5b,d). During the cold period, simulations considering the lowest albedo (the reference simulation), lead to a higher sublimation rate (Fig. 5b). Indeed, a lower albedo increases the energy absorbed by the snowpack, 
https://doi.org/10.5194/tc-2021-9

Preprint. Discussion started: 26 January 2021

(C) Author(s) 2021. CC BY 4.0 License.

(c) (i)

and as the temperature is below the freezing point, this energy leads to an increase in the sublimation. Second, the increase of net SW radiation also affects the physical properties of the snowpack resulting in an increase of compaction (Fig. 3b). The snow density of the snowpack is therefore higher (Fig. S6.1 in SM), which directly affects the thermal conductivity of the upper snow layers (Yen, 1981). Changing the surface temperature is directly linked to the latent heat flux and therefore to the sublimation, explaining the different sublimation ratios simulated depending on the albedo parameterizations.

Contrary to SnowModel, the albedo parameterization of SNOWPACK does not affect the sublimation but strongly influences the melting speed (Fig.5), which can be attributed to the more complex characteristics of this model. SNOWPACK allows refreezing and evaporation of melting snow within the snowpack, which can lead to a longer melt season, whereas calculated evaporation leads to a lower amount of runoff from melt. Also, SNOWPACK considers a more complex representation of snow physics, such as the grain size and the snow surface area (SSA), which directly impacts the albedo and can help to explain the wide diversity of melt simulations.

When comparing the ablation and energy fluxes (Fig. 5 and 6), it is clear that the sublimation rates of both reference runs are very similar (difference of $27.6 \mathrm{~mm}$ w.e. of the cumulative sublimation at 1 September), whereas subtle differences are related to differences in turbulent and latent heat fluxes (average cold period $Q_{L}$ is $-28.3 \mathrm{~W} \mathrm{~m}^{-2}$ for SNOWPACK vs. $-34.5 \mathrm{~W} \mathrm{~m}^{-2}$ for SnowModel).

At the end of the season, the cumulative melt is comparable between the reference simulations of the two models (90.8 $\mathrm{mm}$ w.e. for SNOWPACK and $86.5 \mathrm{~mm}$ w.e. for SnowModel, Fig. 5c,d), although with large differences in melt distribution. For SnowModel, the entire snowpack melts within a few days (i.e. $11.2 \mathrm{~mm}$ w.e. $\mathrm{d}^{-1}$ between 12 and 19 September) while melt is later and slower in SNOWPACK (7.3 mm w.e. $\mathrm{d}^{-1}$ between 18 and 27 September). This corresponds to higher net SW radiation and lower albedo simulations in SnowModel during the melting period (Fig. 6), which increases the energy available for melt and subsequent runoff.

Evaporation and refreezing of meltwater also explain part of the differences in ablation results between the models. SNOWPACK simulates $0.30 \mathrm{~mm}$ w.e. $\mathrm{d}^{-1}$ of evaporation of the liquid water contained in the snowpack (10\% of total ablation corresponding to a total of $28 \mathrm{~mm}$ ) and also allows for refreezing due to the low temperature during the night. These processes, not considered by SnowModel, reduce the runoff simulated by SNOWPACK, whereas SnowModel often encounters the snowpack threshold density to activate direct run-off in the bucket scheme. 
https://doi.org/10.5194/tc-2021-9

Preprint. Discussion started: 26 January 2021

(c) Author(s) 2021. CC BY 4.0 License.

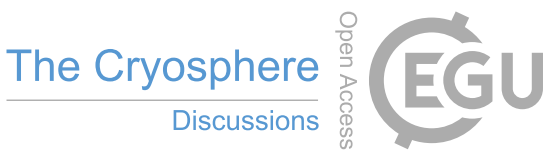
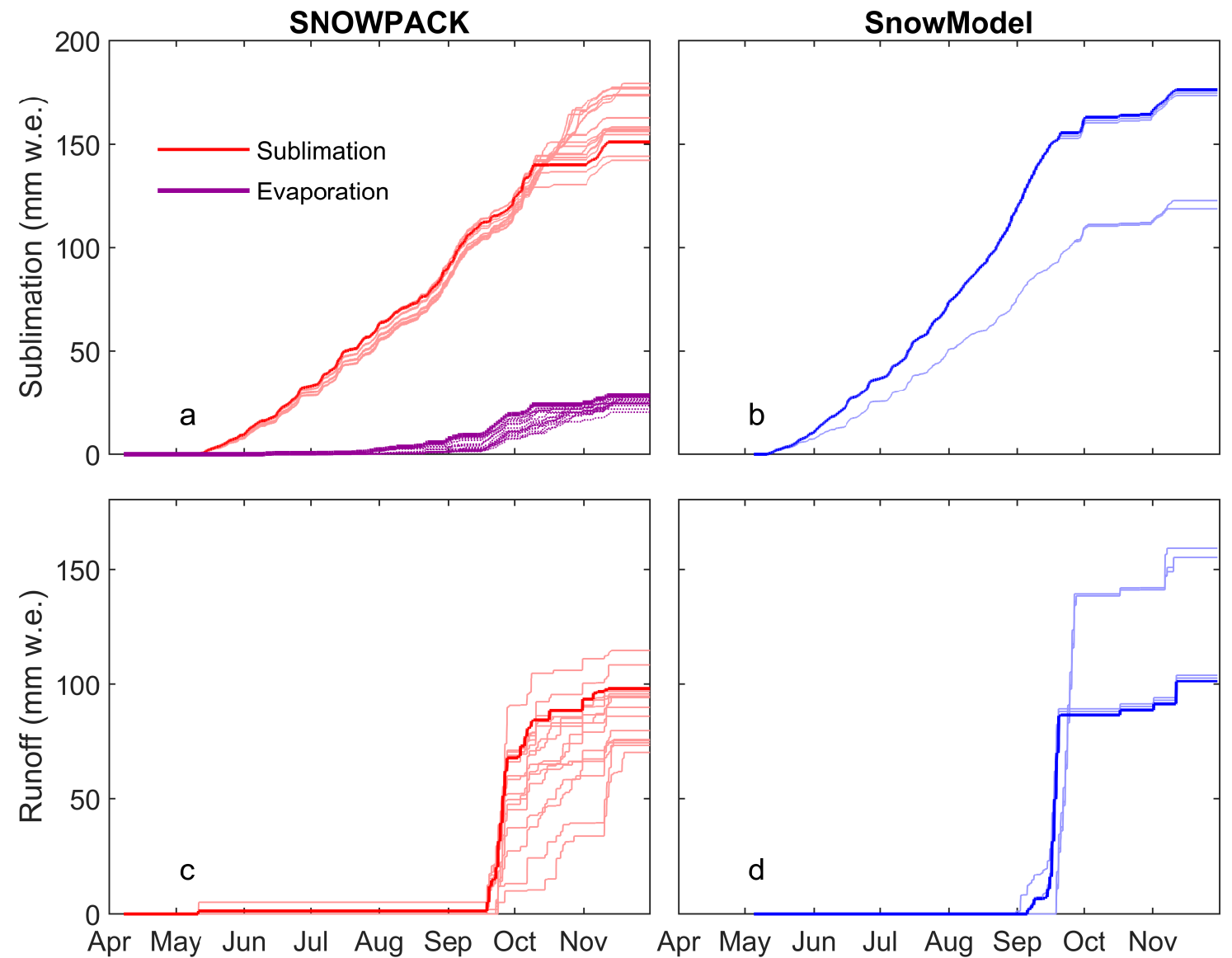

Figure 5. Cumulative sublimation (a,b) and runoff from melt (c,d), simulated by SNOWPACK (red) and SnowModel (blue). For SNOWPACK the cumulative evaporation from melt is shown (purple lines in a). Results for all the ensemble calibrations are shown and the bold lines correspond to the reference simulations of each model. 
https://doi.org/10.5194/tc-2021-9

Preprint. Discussion started: 26 January 2021

(c) Author(s) 2021. CC BY 4.0 License.
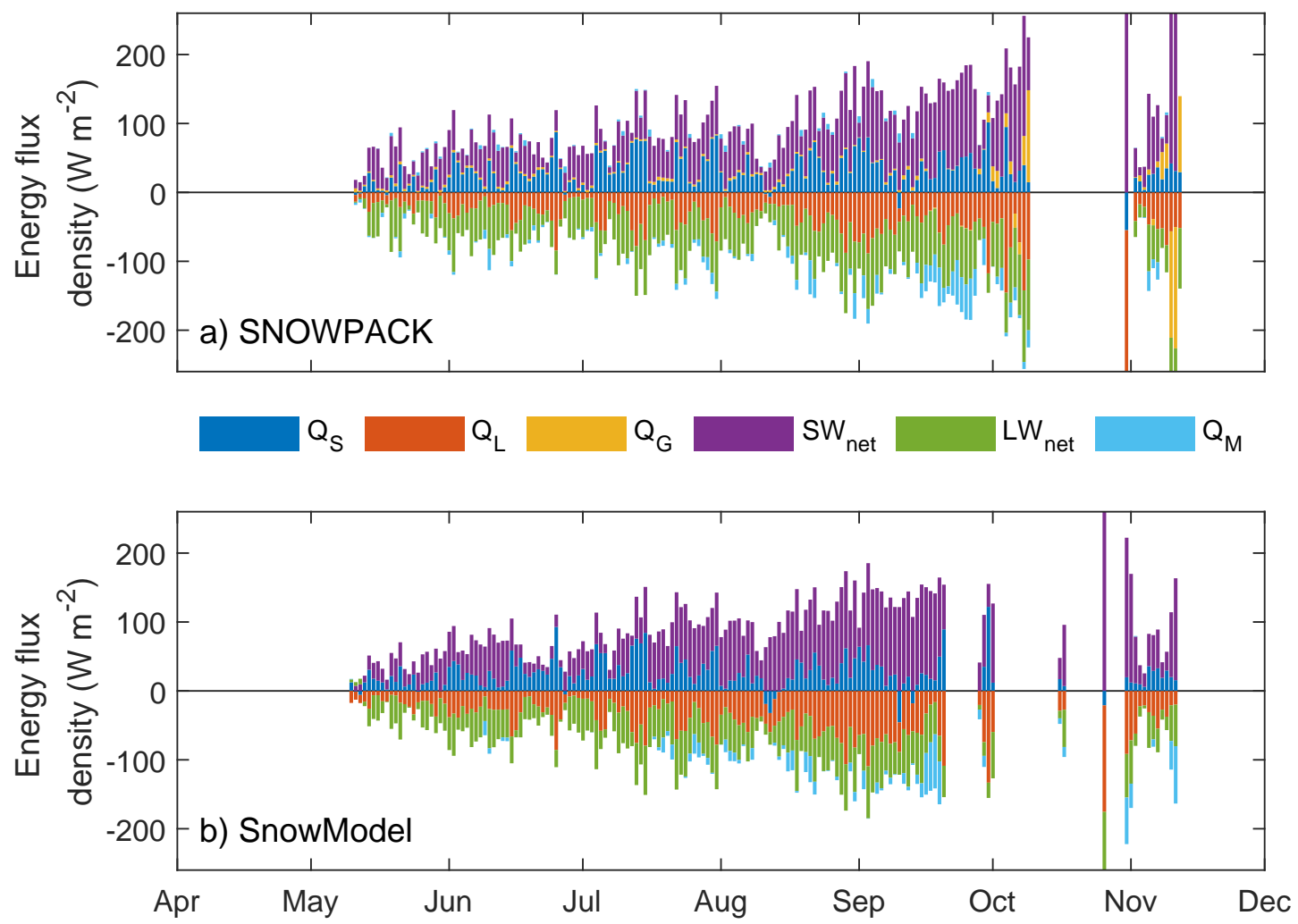

Figure 6. Stacked daily averages of the modelled heat fluxes at Tapado AWS simulated with the reference runs of a) SNOWPACK and b) SnowModel. $S W_{n e t}$ is net shortwave radiation, $L W_{n e t}$ is net longwave radiation, $Q_{S}$ is the sensible heat flux, $Q_{L}$ is the latent heat flux, $Q_{G}$ is the heat flux from the ground (only simulated by SNOWPACK), and $Q_{M}$ is the energy consumed by melt. The fluxes are only plotted at the times where the models simulate snow. 
https://doi.org/10.5194/tc-2021-9

Preprint. Discussion started: 26 January 2021

(c) Author(s) 2021. CC BY 4.0 License.

(c) (i)

\section{Discussion}

\subsection{Model sensitivity and comparison}

Our results show the importance of model parameterization and model structure over the snow model choice, despite the limited model options chosen for the ensemble approach, and the large differences in the two model complexities chosen in this study. This conclusion, found here in an arid environment, is in total agreement with the studies performed in Alpine areas (Etchevers et al., 2004; Günther et al., 2019). Günther et al. (2019) highlighted for instance the importance of the model structure as being higher than the choice of the parameter values.

In this study, the albedo parameterization appears the most important parameter to be properly assessed, as also reported by the studies performed in Alpine regions (Etchevers et al., 2004; Zolles et al., 2019). This can be surprising at first glance as in the semi-arid Andes the ablation is mainly driven by the sublimation and the albedo calibration is generally crucial to accurately simulate the melt. However, according to the results presented here, the two models agree with the larger sensitivity to the albedo parameterization. This is likely related to the absence of the consideration of the uncertainty associated to the turbulent fluxes parameterization in the ensemble approach, while it can have major implications in surface energy balance modelling (e.g. Dadic et al., 2013; Conway and Cullen, 2013; Litt et al., 2017; Réveillet et al., 2020). The representation of turbulent fluxes in snow models is commonly based on the bulk method, and the Richardson number is usually used to evaluate the atmosphere stability (e.g. Liston and Hall, 1995; Vionnet et al., 2012). The roughness value is therefore used to parameterize the turbulent fluxes. While the stability function cannot be compared between the two models chosen in this study, the sensitivity of SNOWPACK to the six possibilities available in the current version is low (i.e. max SD difference of few centimeters, results not shown). In a study over Brewster Glacier in New-Zealand, Conway and Cullen (2013) pointed out the importance of the stability functions to properly simulate the heat fluxes with low wind speed and large temperature gradients and also that the modelled latent heat fluxes were unaffected by the choice of exchange coefficient parameterization. The study takes place in a dry and windy environment without large temperature gradient and thus, this explains the low differences observed related to the chosen atmospheric stability function. The turbulent fluxes parameterization is sensitive to the roughness value and observations such as Eddy Covariance measurements are essential to accurately parameterize the turbulent fluxes (e.g. Conway and Cullen, 2013; Litt et al., 2017; Réveillet et al., 2018). Due to the absence of such measurements, and also due to the strong variability of this value over the time (e.g. MacDonell et al., 2013b; Pellicciotti et al., 2005; Nicholson et al., 2016), a sensitivity analysis was performed (see Sect. S3). Here we varied the value within a random range and found a larger range of uncertainty for SNOWPACK than for SnowModel. This is likely due to the higher complexity in physical representation of SNOWPACK, but it does not allow us to conclude if this uncertainty is higher than the albedo parameterization.

The impact of parameterization choice differs for the two models as the uncertainty is directly related to the difference in snow physical representation and the characteristics of the models. Indeed, the range of the ensemble approach simulated by SNOWPACK is higher than that simulated by SnowModel directly related to both higher calibration choice for SNOWPACK and more complex physical representation of the processes. 
https://doi.org/10.5194/tc-2021-9

Preprint. Discussion started: 26 January 2021

(C) Author(s) 2021. CC BY 4.0 License.

(c) (i)

Likewise, results presented here show that the main sensitivity remains in the forcing uncertainty, in agreement with previous studies (Magnusson et al., 2015; Günther et al., 2019; Raleigh et al., 2015). For instance, (Magnusson et al., 2015) found that the models of different complexity (temperature-index models vs. physical models) show similar ability to reproduce daily observed snowpack runoff, and concluded that the forcing uncertainties is the greatest factor affecting model performance, rather than model parameterizations. However, as mentioned by Raleigh et al. (2015), simulated SD and SWE are critically sensitive to the relative magnitude of errors in forcing. They also mentioned that precipitation bias was the most important factor, in agreement with the findings of our study.

Finally, while Rutter et al. (2009) pointed out that no universal 'best' model exists and model performance strongly depends on the study site, here we show, that in a semi-arid environment, the conclusions are similar for Alpine environments in that model structure and parameterization choices represent an important step to improve model performance.

\subsection{Limitations of the study and further works}

The sensitivity study of the two models to the forcing is done by perturbing the meteorological variables with random noise and does not necessarily preserve the physical consistency. Some studies (e.g. Charrois et al., 2016) maintained this consistency by applying a random perturbation using a first-order auto-regressive model (Deodatis and Shinozuka, 1988). However, the forcing perturbation does not affect the conclusion of the relative comparison of the two models which only requires the exact same forcing as input to be relevant. For the same reason, the choice of method applied for the forcing correction (i.e. for precipitation) and reconstruction (i.e. for the TA and RH) would not affect the conclusions of the model comparison. However, due to the forcing uncertainty related to measurements errors, and also because the sensor locations may not be representative of the area, only a qualitative comparison between the simulated and observed SWE and SD measurement is done in this work. Günther et al. (2019) already outlined that the snow cover is spatially heterogeneous even at very small scales due to topographic and microclimatic effects on accumulation, redistribution, and ablation processes, introducing an uncertainty in validation data. We also show that in any case, due to i) the question of the sensor location representativity of the area, ii) the precipitation undercatch because of the wind, and, iii) the strong sensitivity of models to precipitation uncertainty, this study highlights the complexity and necessity of accurately measuring precipitation.

The ensemble approach of the calibration is built considering limited parameterization options, contrary to other studies where a large number of physical options are considered (e.g. Essery et al., 2013; Lafaysse et al., 2017; Zolles et al., 2019). In our case, choosing snow models with different physical complexities limits the number of calibration possibilities, as calibration of same variables are chosen for the comparison. Thus, some parameterizations, such as the choice of atmospheric stability correction only available in SNOWPACK, were excluded and this model is calibrated following the same options found in SnowModel (Sect. 3.2.1).

Testing different albedo parameterizations is chosen as i) different options are possible in both models and ii) previous studies concluded that the largest absolute uncertainties originate from the shortwave radiation and the albedo parameterizations (e.g. Zolles et al., 2019). The sensitivity test to different fresh snow density parameterizations was also chosen as previous studies 
https://doi.org/10.5194/tc-2021-9

Preprint. Discussion started: 26 January 2021

(C) Author(s) 2021. CC BY 4.0 License.

(c) (i)

identified this calibration as a significant uncertainties in model calibration (e.g. Essery et al., 2013). Finally, energy balance models are known to be sensitive to $z_{0}$, especially in cold and dry regions where sublimation is the main ablation process (e.g. Réveillet et al., 2020). However, due to this important sensitivity and the absence of measurements to properly calibrate this value, the sensitivity test by changing the value within a random range is performed independently (see Sect. S3).

Otherwise, despite the choice of limiting the calibration options, SNOWPACK's sensitivity to model calibration is evaluated based on 20 simulations, whereas SnowModel's evaluation is based on six simulations only. However, the difference of the number of simulation does not impact the conclusion, as the width of the spread of different calibrations was not quantitatively assessed.

Among the possible calibrations, the snow transport option has not been activated, while the option is available in both models. However, due to the strong wind speed characteristics of the study area (Gascoin et al., 2013, and Fig. 2), snow transport is expected to be considerable. Yet, snow transport estimation remains out of the scope of this study, focused on energy balance comparisons, mainly to assess differences in sublimation rates. Also, in a study performed in the Pascua-Lama catchment, a region to the north of Tapado AWS, Gascoin et al. (2013) highlighted that the inclusion of SnowTran3D does not change the fact that the model is unable to capture the small-scale snow depth spatial variability (as captured by in-situ snow depth sensors). Last, snow transport in SNOWPACK can only be simulated with a SD assimilation, which could not be used as validation data. However, due to the importance and complexity in modelling snow transport, properly assessing its impact could be assessed in future work.

\section{Conclusion}

The aim of this study is to compare two snow models, SNOWPACK and SnowModel, and evaluate their sensitivity relative to calibration and forcing. For that purpose, the two models are run over the 2017 snow season, at local point, and forced with i) an ensemble of different physical calibrations and ii) an ensemble of perturbed forcing.

The calibration ensemble simulations were built considering different parameterizations of the albedo and the fresh snow density. Results indicated a significant difference related mainly to the calibration choice of the albedo. However, the impact of this choice affects the two models differently. For SnowModel, the albedo parameterization has a significant impact on the simulated sublimation during the cold period (i.e. difference of $\sim 40 \mathrm{~mm}$ w.e.) while SNOWPACK simulates similar sublimation rates for all the possible calibrations. The albedo parameterization of SNOWPACK has stronger consequences on melt at the end of the season leading to a difference of $45 \mathrm{~mm}$ w.e. of the total melt, and a difference of the end of the season of 41 days, related to the calibration chosen. This model differences are mainly related to the model characteristics (i.e. the consideration of the water evaporation and refreezing into the snowpack), and the more complex representation of the snow physics in SNOWPACK.

415 In addition, results presented in this study highlight a larger uncertainty depending on the model calibration (despite the limited number of options chosen) than between the two models (even though the significant differences in their physical complexity). 
https://doi.org/10.5194/tc-2021-9

Preprint. Discussion started: 26 January 2021

(C) Author(s) 2021. CC BY 4.0 License.

(c) (i)

The sensitivity of both models to the forcing data is highly influenced by the precipitation uncertainties. As for ensemble calibration study, SNOWPACK shows larger uncertainty in modelling the end of the season (i.e. difference of 36 days) compared to SnowModel (i.e. 20 days), likely related to more complex physical processes. SnowModel shows larger uncertainty during the start of the melting period, but, a small difference on the simulated date of the end of the season. This is attributed to the fast melt of the entire snowpack (i.e. few days) simulated by this model.

Otherwise, for both models, results show uncertainty of similar magnitude between the calibration and forcing. However, this result strongly depends on the bias chosen for the forcing perturbation as well as the number of calibrations selected, which, here, does not enable us to draw a conclusion about the larger source of uncertainty or the most appropriate model to model snow depth evolution in the semi-arid Andes. .

This study is performed over one winter season providing conclusions of the model sensitivity, specific for this winter. In further studies, simulations could be performed over a larger time period, and at distinct places to reinforced and discuss the conclusions presented here. In addition, the model choice could be extended to other models, and in particular snow models with similar physical complexity. Such work would provide additional information of the calibration sensitivity by allowing a comparison based on a larger choice of possible calibrations.

Data availability. Part of the data used in this paper (AWS data) can be accessed at https://www.ceazamet.cl. SnowModel can be accessed by contacting the administrator, Glen E. Liston. SNOWPACK is an Open Source and can be accessed at https://models.slf.ch/p/snowpack/. For any other access to the data presented in this study, please contact the authors.

Author contributions. AV conducted data preparation, ran the numerical experiments and produced the figures. AV and MR designed the modelling strategy. MR and SM designed the study. All authors contributed to the results analysis and to the preparation of the paper.

Competing interests. The authors declare that they have no conflict of interest.

Acknowledgements. The authors thank Glen E. Liston for providing the code of SnowModel. We are also grateful to CEAZAmet and the CEAZA glaciology group for maintaining the Tapado AWS and data centre.

Marion Réveillet and Shelley MacDonell were supported by CONICYT-Programa Regional R16A10003, and the Coquimbo regional government FIC-R(2015) BIP 30403127-0. Marion Réveillet was also supported by the ANR program: ANR-16-CE01-0006 EBONI. 
https://doi.org/10.5194/tc-2021-9

Preprint. Discussion started: 26 January 2021

(c) Author(s) 2021. CC BY 4.0 License.

(c) (i)

\section{References}

Ayala, A., Pellicciotti, F., Peleg, N., and Burlando, P.: Melt and surface sublimation across a glacier in a dry environment: distributed energybalance modelling of Juncal Norte Glacier, Chile, Journal of Glaciology, 63, 803-822, https://doi.org/10.1017/jog.2017.46, 2017.

Bartelt, P. and Lehning, M.: A physical SNOWPACK model for the Swiss avalanche warning: Part I: Numerical model, Cold Regions Science and Technology, 35, 123-145, https://doi.org/10.1016/s0165-232x(02)00074-5, 2002.

Bavay, M. and Egger, T.: MeteoIO 2.4. 2: a preprocessing library for meteorological data, Geosci, Model Dev. Discuss, 7, 3595-3645, 2014.

Braithwaite, R. J. and Olesen, O. B.: Calculation of Glacier Ablation from Air Temperature, West Greenland, in: Glaciology and Quaternary Geology, pp. 219-233, Springer Netherlands, https://doi.org/10.1007/978-94-015-7823-3_15, 1989.

Brock, B. W., Willis, I. C., and Sharp, M. J.: Measurement and parameterization of albedo variations at Haut Glacier d'Arolla, Switzerland, Journal of Glaciology, 46, 675-688, https://doi.org/10.3189/172756500781832675, 2000.

Brock, B. W., Willis, I. C., and Sharp, M. J.: Measurement and parameterization of aerodynamic roughness length variations at Haut Glacier d'Arolla, Switzerland, Journal of Glaciology, 52, 281-297, https://doi.org/10.3189/172756506781828746, 2006.

Charrois, L., Cosme, E., Dumont, M., Lafaysse, M., Morin, S., Libois, Q., and Picard, G.: On the assimilation of optical reflectances and snow depth observations into a detailed snowpack model, The Cryosphere, 10, 1021-1038, https://doi.org/10.5194/tc-10-1021-2016, 2016.

Conway, J. P. and Cullen, N. J.: Constraining turbulent heat flux parameterization over a temperate maritime glacier in New-Zealand, Annals of Glaciology, 54, 41-51, https://doi.org/10.3189/2013aog63a604, 2013.

Dadic, R., Mott, R., Lehning, M., Carenzo, M., Anderson, B., and Mackintosh, A.: Sensitivity of turbulent fluxes to wind speed over snow surfaces in different climatic settings, Advances in Water Resources, 55, 178-189, https://doi.org/10.1016/j.advwatres.2012.06.010, 2013.

Deodatis, G. and Shinozuka, M.: Auto-Regressive Model for Nonstationary Stochastic Processes, Journal of Engineering Mechanics, 114, 1995-2012, https://doi.org/10.1061/(asce)0733-9399(1988)114:11(1995), 1988.

Douville, H., Royer, J.-F., and Mahfouf, J.-F.: A new snow parameterization for the Météo-France climate model. Part I: validation in standalone experiments, Climate Dynamics, 12, 21-35, https://doi.org/10.1007/s003820050092, 1995.

Dutra, E., Balsamo, G., Viterbo, P., Miranda, P. M. A., Beljaars, A., Schär, C., and Elder, K.: An Improved Snow Scheme for the ECMWF Land Surface Model: Description and Offline Validation, Journal of Hydrometeorology, 11, 899-916, https://doi.org/10.1175/2010jhm1249.1, 2010.

Essery, R., Morin, S., Lejeune, Y., and Ménard, C. B.: A comparison of 1701 snow models using observations from an alpine site, Advances in Water Resources, 55, 131-148, https://doi.org/10.1016/j.advwatres.2012.07.013, 2013.

Etchevers, P., Martin, E., Brown, R., Fierz, C., Lejeune, Y., Bazile, E., Boone, A., Dai, Y.-J., Essery, R., Fernandez, A., Gusev, Y., Jordan, R., Koren, V., Kowalczyk, E., Nasonova, N. O., Pyles, R. D., Schlosser, A., Shmakin, A. B., Smirnova, T. G., Strasser, U., Verseghy, D., Yamazaki, T., and Yang, Z.-L.: Validation of the energy budget of an alpine snowpack simulated by several snow models (Snow MIP project), Annals of Glaciology, 38, 150-158, https://doi.org/10.3189/172756404781814825, 2004.

Favier, V., Falvey, M., Rabatel, A., Praderio, E., and López, D.: Interpreting discrepancies between discharge and precipitation in high-altitude area of Chile's Norte Chico region (26-32 ${ }^{\circ}$ S), Water Resources Research, 45, https://doi.org/10.1029/2008wr006802, 2009.

Gascoin, S., Lhermitte, S., Kinnard, C., Bortels, K., and Liston, G. E.: Wind effects on snow cover in Pascua-Lama, Dry Andes of Chile, Advances in Water Resources, 55, 25-39, https://doi.org/10.1016/j.advwatres.2012.11.013, 2013. 
https://doi.org/10.5194/tc-2021-9

Preprint. Discussion started: 26 January 2021

(c) Author(s) 2021. CC BY 4.0 License.

(c) (i)

Günther, D., Marke, T., Essery, R., and Strasser, U.: Uncertainties in Snowpack Simulations-Assessing the Impact of Model Structure, Parameter Choice, and Forcing Data Error on Point-Scale Energy Balance Snow Model Performance, Water Resources Research, 55, 2779-2800, https://doi.org/10.1029/2018wr023403, 2019.

Hock, R.: Temperature index melt modelling in mountain areas, Journal of Hydrology, 282, 104-115, https://doi.org/10.1016/s00221694(03)00257-9, 2003.

Lafaysse, M., Cluzet, B., Dumont, M., Lejeune, Y., Vionnet, V., and Morin, S.: A multiphysical ensemble system of numerical snow modelling, The Cryosphere, 11, 1173-1198, https://doi.org/10.5194/tc-11-1173-2017, 2017.

Lehning, M., Bartelt, P., Brown, B., and Fierz, C.: A physical SNOWPACK model for the Swiss avalanche warning: Part III: Meteorological forcing, thin layer formation and evaluation, Cold Regions Science and Technology, 35, 169-184, https://doi.org/10.1016/s0165232x(02)00072-1, 2002a.

Lehning, M., Bartelt, P., Brown, B., Fierz, C., and Satyawali, P.: A physical SNOWPACK model for the Swiss avalanche warning: Part II: Snow microstructure, Cold Regions Science and Technology, 35, 147-167, https://doi.org/10.1016/s0165-232x(02)00073-3, 2002b.

Lehning, M., Völksch, I., Gustafsson, D., Nguyen, T. A., Stähli, M., and Zappa, M.: ALPINE3D: a detailed model of mountain surface processes and its application to snow hydrology, Hydrological Processes, 20, 2111-2128, https://doi.org/10.1002/hyp.6204, 2006.

490 Liston, G. E. and Elder, K.: A Meteorological Distribution System for High-Resolution Terrestrial Modeling (MicroMet), Journal of Hydrometeorology, 7, 217-234, https://doi.org/10.1175/jhm486.1, 2006a.

Liston, G. E. and Elder, K.: A Distributed Snow-Evolution Modeling System (SnowModel), Journal of Hydrometeorology, 7, 1259-1276, https://doi.org/10.1175/jhm548.1, 2006b.

Liston, G. E. and Hall, D. K.: An energy-balance model of lake-ice evolution, Journal of Glaciology, 41, 373-382, https://doi.org/10.3189/s0022143000016245, 1995.

Liston, G. E. and Sturm, M.: A snow-transport model for complex terrain, Journal of Glaciology, 44, 498-516, https://doi.org/10.3189/s0022143000002021, 1998.

Litt, M., Sicart, J.-E., Six, D., Wagnon, P., and Helgason, W. D.: Surface-layer turbulence, energy balance and links to atmospheric circulations over a mountain glacier in the French Alps, The Cryosphere, 11, 971-987, https://doi.org/10.5194/tc-11-971-2017, 2017.

500 MacDonald, J. and Pomeroy, J.: Gauge undercatch of two common snowfall gauges in a prairie environment, in: Proceedings of the 64th Eastern Snow Conference, vol. 29, pp. 119-126, 2007.

MacDonell, S., Kinnard, C., Mölg, T., Nicholson, L., and Abermann, J.: Meteorological drivers of ablation processes on a cold glacier in the semi-arid Andes of Chile, The Cryosphere, 7, 1513-1526, https://doi.org/10.5194/tc-7-1513-2013, $2013 \mathrm{a}$.

MacDonell, S., Nicholson, L., and Kinnard, C.: Parameterisation of incoming longwave radiation over glacier surfaces in the semi-arid Andes of Chile, Theoretical and Applied Climatology, 111, 513-528, https://doi.org/10.1007/s00704-012-0675-1, 2013b.

Magnusson, J., Wever, N., Essery, R., Helbig, N., Winstral, A., and Jonas, T.: Evaluating snow models with varying process representations for hydrological applications, Water Resources Research, 51, 2707-2723, https://doi.org/10.1002/2014wr016498, 2015.

Mengual Henríquez, S. A.: Caracterización de la nieve de distintas localidades de Chile mediante el uso del modelo SNOWPACK, Master's thesis, Universidad de Chile, 2017.

510 Nicholson, L. I., Pętlicki, M., Partan, B., and MacDonell, S.: 3-D surface properties of glacier penitentes over an ablation season, measured using a Microsoft Xbox Kinect, The Cryosphere, 10, 1897-1913, https://doi.org/10.5194/tc-10-1897-2016, 2016.

Oke, T. R.: Boundary layer climates, Routledge, 2002. 
https://doi.org/10.5194/tc-2021-9

Preprint. Discussion started: 26 January 2021

(c) Author(s) 2021. CC BY 4.0 License.

(c) (i)

Pellicciotti, F., Brock, B., Strasser, U., Burlando, P., Funk, M., and Corripio, J.: An enhanced temperature-index glacier melt model including the shortwave radiation balance: development and testing for Haut Glacier d'Arolla, Switzerland, Journal of Glaciology, 51, 573-587, https://doi.org/10.3189/172756505781829124, 2005.

Rabatel, A., Castebrunet, H., Favier, V., Nicholson, L., and Kinnard, C.: Glacier changes in the Pascua-Lama region, Chilean Andes (29 S): recent mass balance and 50 yr surface area variations, The Cryosphere, 5, 1029-1041, https://doi.org/10.5194/tc-5-1029-2011, 2011.

Raleigh, M. S., Lundquist, J. D., and Clark, M. P.: Exploring the impact of forcing error characteristics on physically based snow simulations within a global sensitivity analysis framework, Hydrology and Earth System Sciences, 19, 3153-3179, https://doi.org/10.5194/hess-193153-2015, 2015.

Randall, K. L.: Campbell Scientific Web Request (case:83574), Personal communication, 2018.

Réveillet, M., Six, D., Vincent, C., Rabatel, A., Dumont, M., Lafaysse, M., Morin, S., Vionnet, V., and Litt, M.: Relative performance of empirical and physical models in assessing the seasonal and annual glacier surface mass balance of Saint-Sorlin Glacier (French Alps), The Cryosphere, 12, 1367-1386, https://doi.org/10.5194/tc-12-1367-2018, 2018.

Réveillet, M., MacDonell, S., Gascoin, S., Kinnard, C., Lhermitte, S., and Schaffer, N.: Impact of forcing on sublimation simulations for a high mountain catchment in the semiarid Andes, The Cryosphere, 14, 147-163, https://doi.org/10.5194/tc-14-147-2020, 2020.

Rutter, N., Essery, R., Pomeroy, J., Altimir, N., Andreadis, K., Baker, I., Barr, A., Bartlett, P., Boone, A., Deng, H., Douville, H., Dutra, E., Elder, K., Ellis, C., Feng, X., Gelfan, A., Goodbody, A., Gusev, Y., Gustafsson, D., Hellström, R., Hirabayashi, Y., Hirota, T., Jonas, T., Koren, V., Kuragina, A., Lettenmaier, D., Li, W.-P., Luce, C., Martin, E., Nasonova, O., Pumpanen, J., Pyles, R. D., Samuelsson, P., Sandells, M., Schädler, G., Shmakin, A., Smirnova, T. G., Stähli, M., Stöckli, R., Strasser, U., Su, H., Suzuki, K., Takata, K., Tanaka, K., Thompson, E., Vesala, T., Viterbo, P., Wiltshire, A., Xia, K., Xue, Y., and Yamazaki, T.: Evaluation of forest snow processes models (SnowMIP2), Journal of Geophysical Research, 114, https://doi.org/10.1029/2008jd011063, 2009.

Scaff, L., Rutllant, J. A., Rahn, D., Gascoin, S., and Rondanelli, R.: Meteorological Interpretation of Orographic Precipitation Gradients along an Andes West Slope Basin at 30 $\mathrm{S}$ (Elqui Valley, Chile), Journal of Hydrometeorology, 18, 713-727, https://doi.org/10.1175/jhmd-16-0073.1, 2017.

Schmucki, E., Marty, C., Fierz, C., and Lehning, M.: Evaluation of modelled snow depth and snow water equivalent at three contrasting sites in Switzerland using SNOWPACK simulations driven by different meteorological data input, Cold Regions Science and Technology, 99 , 27-37, https://doi.org/10.1016/j.coldregions.2013.12.004, 2014.

Smith, C. D.: Correcting the wind bias in snowfall measurements made with a Geonor T-200B precipitation gauge and alter wind shield, in: 87th American Meteorological Society Annual Meeting, San Antonio, TX, 2007.

Strack, J. E., Liston, G. E., and Pielke Sr, R. A.: Modeling snow depth for improved simulation of snow-vegetation-atmosphere interactions, Journal of Hydrometeorology, 5, 723-734, 2004.

Strasser, U. and Marke, T.: ESCIMO.spread - a spreadsheet-based point snow surface energy balance model to calculate hourly snow water equivalent and melt rates for historical and changing climate conditions, Geoscientific Model Development, 3, 643-652, https://doi.org/10.5194/gmd-3-643-2010, 2010.

Vionnet, V., Brun, E., Morin, S., Boone, A., Faroux, S., Moigne, P. L., Martin, E., and Willemet, J.-M.: The detailed snowpack scheme Crocus and its implementation in SURFEX v7.2, Geoscientific Model Development, 5, 773-791, https://doi.org/10.5194/gmd-5-773-2012, 2012.

Weiser, U., Olefs, M., Schöner, W., Weyss, G., and Hynek, B.: Correction of broadband snow albedo measurements affected by unknown slope and sensor tilts, The Cryosphere, 10, 775-790, https://doi.org/10.5194/tc-10-775-2016, 2016. 
https://doi.org/10.5194/tc-2021-9

Preprint. Discussion started: 26 January 2021

(C) Author(s) 2021. CC BY 4.0 License.

(c) (1)

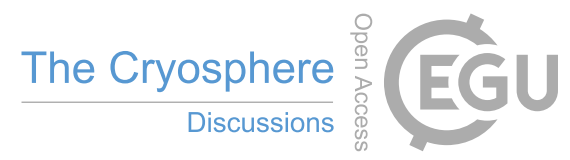

550 Wever, N., Fierz, C., Mitterer, C., Hirashima, H., and Lehning, M.: Solving Richards Equation for snow improves snowpack meltwater runoff estimations in detailed multi-layer snowpack model, The Cryosphere, 8, 257-274, https://doi.org/10.5194/tc-8-257-2014, 2014.

Wolff, M. A., Isaksen, K., Petersen-Øverleir, A., Ødemark, K., Reitan, T., and Brækkan, R.: Derivation of a new continuous adjustment function for correcting wind-induced loss of solid precipitation: results of a Norwegian field study, Hydrology and Earth System Sciences, 19, 951-967, https://doi.org/10.5194/hess-19-951-2015, 2015.

555 Wright, M.: Performance Analysis of CS725 Snow Water Equivalent Sensor, Edmonton, AB: Campbell Scientific Corp, 2011.

Yen, Y.-C.: Review of thermal properties of snow, ice, and sea ice, vol. 81, US Army, Corps of Engineers, Cold Regions Research and Engineering Laboratory, 1981.

Zolles, T., Maussion, F., Galos, S. P., Gurgiser, W., and Nicholson, L.: Robust uncertainty assessment of the spatio-temporal transferability of glacier mass and energy balance models, The Cryosphere, 13, 469-489, https://doi.org/10.5194/tc-13-469-2019, 2019. 